\title{
The syndromes of Marshall and Weaver
}

\author{
NAOMI FITCH \\ From the Lady Davis Institute for Medical Research, Jewish General Hospital, \\ 3755 Cote Saint Catherine Road, Montreal, Quebec, Canada H3T 1E2
}

SUMMARY Several investigators have suggested that the Marshall syndrome and the Weaver syndrome are one entity because of some phenotypic overlap. This paper reviews the findings in nine additional patients with the Marshall syndrome and concludes that the syndromes are two distinct entities. In the Marshall syndrome there is a characteristic facies, failure to thrive in terms of height, weight, and psychomotor development, and early death. In the Weaver syndrome the infants thrive too well: weight and height are much above normal. They also have increased bifrontal diameter, hypertonia, prominent finger pads, and thin, deep-set nails, and the face is quite different from the Marshall facies.

In 1971 Marshall et al ${ }^{1}$ described a syndrome of accelerated skeletal maturation and failure to thrive in two infants. At least nine more patients with this syndrome have been identified. ${ }^{2-10}$ A second new syndrome of accelerated maturation was described by Weaver $e t$ al $^{11}$ in two boys. Additional features consisted of overgrowth in height and weight, unusual facies, and camptodactyly. Several investigators $^{51213}$ have suggested that the Marshall syndrome and the Weaver syndrome may be the same entity. All cases of these syndromes have been analysed in order to delineate further the syndromes and to determine whether any evidence could be gathered for or against the hypothesis that the two syndromes are one entity.

\section{The Marshall syndrome}

A review of 11 patients showed that there was no parental consanguinity and there were no sibs or other relatives with similar defects. Two mothers of infants with the Marshall syndrome took drugs during the pregnancy. One ${ }^{5}$ took thyroxine for the first 6 months of the pregnancy; another ${ }^{7}$ took heroin throughout the pregnancy and methadone in the last 3 months. The abnormalities which occurred most frequently in the 11 patients are presented in table 1 . Long hands or fingers, prominent forehead, or frontal bossing were noted in seven cases; upturned nares, long feet, herniae, and shallow orbits in six; blue sclerae, hypertrichosis, and long thin tubular bones in five; low-set ears, scoliosis, and increased skull density in four. Camptodactyly, Received for publication 19 June 1979
TABLE 1 Frequency of anomalies in 11 patients with the Marshall syndrome

\begin{tabular}{lc}
\hline Accelerated skeletal maturation & 11 \\
Abnormal middle phalanges in hands & 11 \\
Psychomotor delay & $5 / 5$ \\
Poor weight gain & $6 / 6$ \\
Pneumonia & 10 \\
Prominent frontal calvarium & 10 \\
Low nose bridge & 10 \\
Proptosis & 10 \\
Small facial bones & 9 \\
Micrognathia & 8 \\
Respiratory problems & 8 \\
\hline
\end{tabular}

hypertelorism, antimongoloid slant, heart defect, small nose, long philtrum, choanal atresia or $\frac{0}{0}$ stenosis, large ears, and feeding difficulty have been reported three times; coarse eyebrows, small mouth, $\delta$ narrow thorax, high-arched palate, megacornea, $₹$ prominent heels, clinodactyly, low-set thumbs, and o floppy ears twice; and increased bitemporal diameter, wide distal femora, abnormal vertebrae, ㅇㅡㅡ abnormal pelvis, hydronephrosis, long phallus, spoon nails, microphthalmia, prehensile toes, and loose 0 skin were each reported once. Further data are N presented in table 2 .

TABLE 2 Eleven newborn with the Marshall syndrome

\begin{tabular}{|c|c|c|c|}
\hline Centile & Weight & Length & Circumference \\
\hline$<3$ rd & 4 & & 1 \\
\hline $3 r d-25$ th & 1 & 1 & $i$ \\
\hline 25 th -50 th & 1 & 1 & 1 \\
\hline 50th-90th & 4 & 3 & 1 \\
\hline$>90$ th & 1 & 5 & 3 \\
\hline
\end{tabular}


There is a characteristic facies which is well illustrated in the papers of Marshall et al, ${ }^{1}$ de Toni et $a l^{6}$ and Iafusco et $a l .^{8} \mathrm{~A}$ prominent calvarium, small facial bones, proptosis, blue sclerae, flat nose bridge, upturned nares, and micrognathia are components of the Marshall facies. Other important features of this syndrome are failure to thrive and severe respiratory difficulties. The infants are usually below the 3rd centile in height and weight. Severe cyanosis is common and often necessitated intubation. Almost every infant developed pneumonia and early death is common. Six died before 6 months of age, and one died at 20 months. Smith (1979, personal communication) reported that the second patient of Marshall has also died. The cause of death has not yet been clarified. One patient ${ }^{4}$ had a rudimentary epiglottis. A persistent ductus arteriosus was noted twice, ${ }^{3} 7$ atrial septal defect once, ${ }^{7}$ and medial hypertrophy of the medium and small pulmonary arteries once. ${ }^{7}$

Radiography confirmed the impression that the facial bones were small and the calvarium relatively prominent. The orbits were shallow, which could explain the proptosis. Abnormal bone formation is indicated by reports of increased bone density of the skull, ${ }^{39}$ a thickened cranial vault, ${ }^{1510}$ and a thin diploë. ${ }^{6}$ Coarse, irregular, and fragmented epiphyses were noted by Hassan et $a l,{ }^{5}$ heterogeneous epiphyses by Ferran et al, ${ }^{9}$ large femoral and proximal epiphyses by Flatz and Natzschka, ${ }^{10}$ and osteoporosis by de Toni et al. ${ }^{6}$ Thin long bones were reported in five patients. ${ }^{1256}$ Ferran et $a l^{9}$ noted hexagonal lumbar vertebrae, mongoloid type pelvis, and heterogeneity of the calcaneus.

Every patient with the Marshall syndrome has abnormalities of the phalanges and sometimes the metacarpals are also abnormal. ${ }^{35910}$ In seven cases the proximal phalanges are widened, in 11 the middle phalanges are widened, and seven have narrow distal phalanges. Study of the hand $x$-rays is particularly interesting because of the presence of a rare abnormality, that is, abnormal modelling of the proximal and middle phalanges. The wide middle phalanx noted in all the reports is rarely of normal shape. The middle phalanges often have a bullet shape, and the proximal phalanges often assume a rectangular shape with rounding at the distal end (fig 1). The same pattern is typical of the Hurler syndrome, but all tests for mucopolysaccharidosis have been normal. The bone age of each patient is given in table 3 .

There is dysharmonic bone maturation; the carpal age is further advanced than the phalangeal age. Pattern profiles are presented in fig 2 . The epiphysis is supposed to be included in the length measurements but in the 17 month profile the measurements

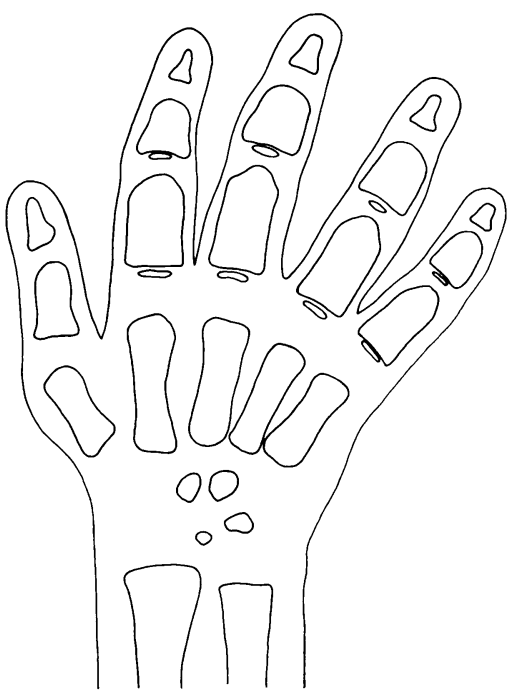

FIG 1 Hand of a 15-day-old infant with the Marshall syndrome (based on fig 4 of Ferran et al ${ }^{y}$ ). Note premature ossification of carpals and phalangeal epiphyses, abnormal shape of middle phalanges 3 to 5 and proximal phalanges 2 to 5 , and small distal phalanges.

TABLE 3 Age, sex, and bone age of patients with the Marshall syndrome

\begin{tabular}{|c|c|c|c|}
\hline Author & Age & $\operatorname{Sex}$ & $\begin{array}{l}\text { Bone age } \\
(y r)\end{array}$ \\
\hline Marshall et al $1^{1}$ & $\begin{array}{l}6 \text { months } \\
16 \text { months }\end{array}$ & $\mathbf{M}$ & $\begin{array}{l}3-6 \\
6\end{array}$ \\
\hline Marshall et al $2^{1}$ & 3 months & $\mathbf{M}$ & $41 / 2$ \\
\hline Nábrády and Bozalyi2 & 9 months & $\mathbf{F}$ & $51 / 2$ \\
\hline Tipton et al ${ }^{3}$ & Newborn & $\mathbf{F}$ & $2-3$ \\
\hline Visveshwara et al 4 & 2 weeks & $\mathbf{M}$ & $3-4$ \\
\hline Hassan et al 5 & 9 days & $\mathbf{F}$ & $11 / 2-2$ \\
\hline de Toni et al 6 & 17 months & $\mathbf{M}$ & 4 \\
\hline Perrin et al $^{7}$ & $\begin{array}{l}\text { Newborn } \\
3 \text { months }\end{array}$ & $\mathbf{M}$ & $\begin{array}{l}13 / 4 \\
3\end{array}$ \\
\hline Iafusco et al 8 & Newborn & $\mathbf{F}$ & $21 / 2$ \\
\hline Ferran et al 9 & 15 days & $\mathbf{M}$ & 2 \\
\hline Flatz and Natzschka & 18 days & $\mathbf{F}$ & Not given \\
\hline
\end{tabular}

do not include the epiphyses of distal phalanges 2 to 5 , all middle phalanges, proximal phalanges 1 and 5 , and metacarpals 1 and 5 because they are not usually present at this age. In the 27 month profile the epiphysis of metacarpal 1, proximal 1, and distals 2 to 5 are omitted for the same reason. The increased length of the bones in the proximal part of the hand is striking and seems consistent with the finding of more advanced maturation of the carpals than the phalanges, that is, it seems as if the main premature ossification is in the proximal part of the hand. 


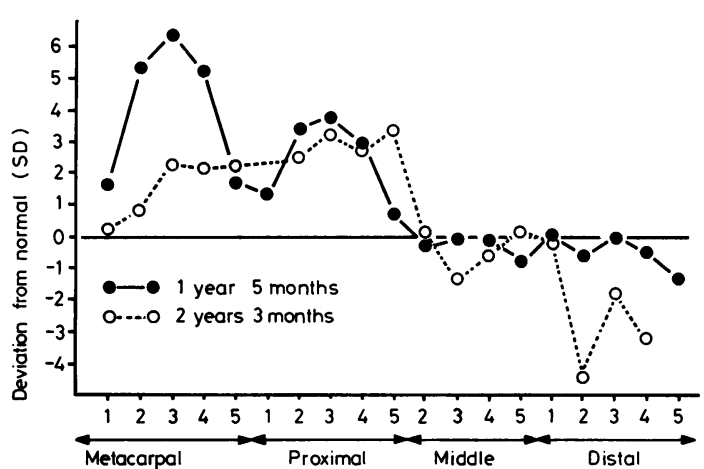

FIG 2 Pattern profile of the hands of the patient of de Toni et $a^{6}$ with the Marshall syndrome at 17 months and at 35 months.

A biopsy of the femur ${ }^{6}$ was reported as 'osteodysplasia of a fibrotic nature'. The humeral head and distal femur studied at necropsy ${ }^{7}$ showed that the zone of provisional calcification appeared foreshortened and the cartilaginous columns in the epiphysis were short. Islands of cartilage persisted in the osteoid trabeculae.

At necropsy, abnormalities of the the brain were noted in three infants. Marshall et $a^{1}$ described broad convolutions in the occipitoparietal area, Tipton et $a l^{3}$ observed abnormal gyral patterns of the brain with macrogyria of the occipital and temporal regions, and Perrin et al $^{7}$ noted moderately dilated lateral ventricles, thinned white matter, mild astrocytic gliosis, and individual neuronal necrosis.

There was one report of low gamma globulin, ${ }^{6}$ one in which testosterone was raised in a female, ${ }^{5}$ and one in which the CK and urine creatinine were raised. ${ }^{10}$ All other laboratory investigations were normal.

Marshall et al ${ }^{1}$ pointed out that the advanced bone maturation could be a true acceleration, or it could be the result of a mesenchymal defect which results in early mineralisation of the secondary centres of ossification. The pathology reports, the modelling errors in the hand bones, the abnormal epiphyses, the increased density and thickness of the skull, as well as all the other numerous defects in this syndrome, suggest that this is not simply a syndrome of precocious bone development, but rather some generalised, often lethal, defect which affects bone and many other tissues.

\section{The Weaver syndrome}

The two boys described by Weaver et al ${ }^{11}$ were characterised by excessive growth of prenatal onset, hypertonia, excessive appetite, large bifrontal dia- meter, flat occiput, large ears, ocular hypertelorism, long philtrum, relative micrognathia, prominent finger pads, camptodactyly, broad thumbs, thin deep-set nails, clinodactyly of the toes, limited elbow and knee extension which improved with age, widened distal femora and ulnae, excess loose skin, inverted nipples, thin hair, herniae, and a hoarse low-pitched cry. At the age of $1 \frac{1}{2}$, heights, weights, and bone ages were much above normal. Smith (1979, personal communication) reported that the two boys have both slowed down to a somewhat more normal rate of growth and both seem to be moderately retarded. Weaver pointed out that although a number of the features noted in these boys were also found in the two infants described by Marshall, the important differences were excessive postnatal growth, hypertonia, increased bifrontal diameter, and broad distal femora. Excessive postnatal growth, hypertonia, and increased bifrontal diameter have not been reported in the additional nine cases of the Marshall syndrome, but wide distal femoral epiphyses have been noted once. ${ }^{5}$ Excessive appetite, prominent finger pads, thin deep-set nails, broad thumbs, excess loose skin, inverted nipples, and thin hair are other features not present in the nine new patients with the Marshall syndrome. The prominent finger pads should be emphasised, as this is a rare dysmorphic sign.

Another infant who may have the Weaver syndrome is described by Moreno et al ${ }^{14}$ and Moreno ${ }^{15}$. He was above the 97th centile in height, weight, and head circumference. He had a hoarse cry, micrognathia, prominent ears, hernia, loose skin, limited movements of some joints, hypertonia, broad trumpet-shaped metaphyses of the long bones, large epiphyses, and advanced bone age. He also had some abnormalities not present in the two infants described by Weaver: prominent superciliary arches with deep-set eyes, small fontanelles, a defect in the occipital bone, prominent cranial sutures, pseudoepiphyses in proximal phalanges 3 and 4 in the hands, ossification defects in the vertebrae, and pelvic abnormalities.

\section{Discussion}

In our opinion the Marshall syndrome and the $\omega$ Weaver syndrome are two distinct entities. One is characterised by a prominent calvarium, small facial $\stackrel{\circ}{\varnothing}$ bones, proptosis, flat nasal bridge, upturned nares, failure to thrive, respiratory problems, and early ${ }_{-}^{+}$ death. The other is a syndrome of overgrowth, hyper- $\frac{0}{0}$ tonia, increased bifrontal diameter, and prominent $\frac{\mathrm{D}}{\mathbb{D}}$ finger pads with thin deep-set nails. Smith ${ }^{16}$ thought $\frac{?}{\mathbb{Q}}$

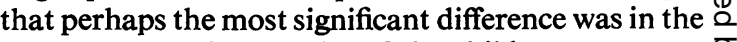
apparent growth potential of the children. 
Bosch-Banyeras et $a l^{12}$ described an infant as having features of both the Marshall syndrome and the Weaver syndrome. The infant weighed $3600 \mathrm{~g}$ at birth, and later heights and weights are shown in fig 3 . The child was well until 1 month when he developed cyanosis at meals; a cardiopathy was discovered at that time (no further details of the cardiac status are presented). He had advanced bone age, hypertelorism, micrognathia, high palate, carp mouth, large low-set ears, umbilical hernia, cryptorchidism, and hypertonia. His fingers were held in a clenched position but camptodactyly was not present. Clinodactyly was present in the fifth fingers, and the proximal and middle phalanges in both hands and feet were said to be widened. The femora showed distal enlargement. He was mentally retarded.

This infant probably has the Weaver syndrome. There is overgrowth (albeit much less than in the original two cases), hypertonia, large ears, hypertelorism, long philtrum, micrognathia, and widened distal femora, all features of the Weaver syndrome, although there is no comment on the more specific features, namely the prominent finger pads and the deep-set nails. The infant does not have the Marshall facies, namely the small facial bones, the prominent calvarium, the low nose bridge, proptosis, short nose with upturned nares, and the failure to thrive that are so common in this syndrome.

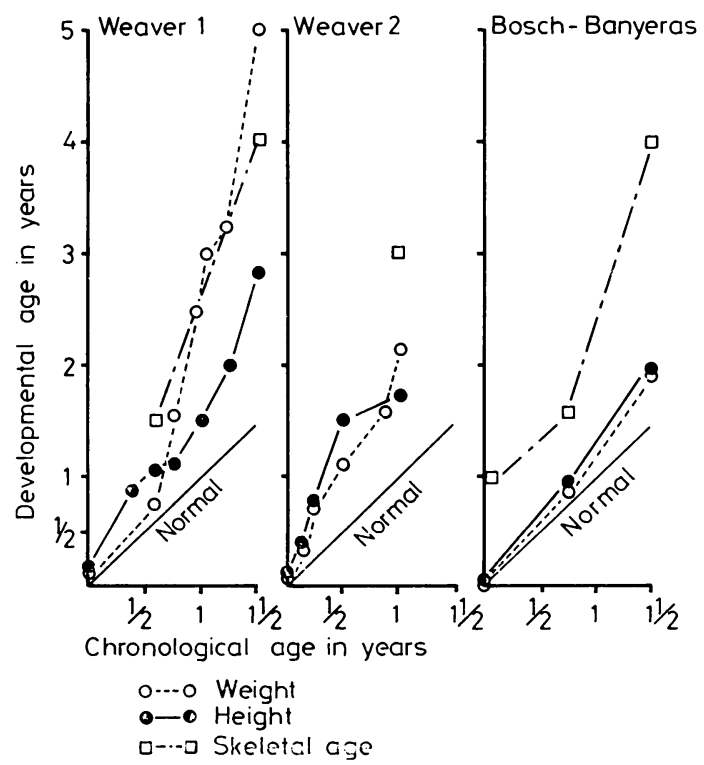

FIG 3 Growth rates of the two patients of Weaver et al 11 and the case of Bosch-Banyeras et al. ${ }^{12}$
The observation of enlargement of the proximal and middle phalanges is interesting. Most $x$-rays of the hands of infants with the Marshall syndrome show a much more marked widening of some phalanges, and metacarpal and phalangeal epiphyses are usually present at this age. These epiphyses were absent in this infant. To assess this report of phalangeal widening we await further descriptions of infants with the Weaver syndrome. It is interesting that no further cases of the Weaver syndrome have been described. Perhaps the dysmorphic features of such children are easy to overlook and unless $x$-rays are taken, children with this syndrome could be missed.

The infant described by Shimura et $a l^{13}$ as having the Marshall syndrome presents a challenge because this patient does not seem to fit into either syndrome as they have just been characterised. There is no mention of small facial bones (although perhaps this was implied by the finding of a relatively large calvarium). The infant does not have the Marshall facies, the severe failure to thrive, or the phalangeal abnormalities. Nor does the infant have the excessive growth, hypertonia, prominent finger pads, thin deep-set nails, broad thumbs, excess loose skin, inverted nipples, and thin hair described by Weaver. We suggest that this infant should not be identified with either one of these syndromes until many more cases of both syndromes have been described.

We would like to comment on the arguments used by the authors who feel there is no real difference between the two syndromes. Hassan et $\mathrm{al}^{5}$ state that the facial dysmorphism is the same. We cannot agree with this statement. The infants described by Weaver do not have the small facial bones, proptosis, and low nasal bridge with upturned nares characteristic of the Marshall facies. Instead they have a broad forehead, hypertelorism, and a rather happy expression as contrasted to the distressed appearance found in so many infants with the Marshall syndrome. Hassan's paper states that the psychomotor development is advanced in the first patient of Weaver; this is an error. Weaver et $^{\mathbf{a l}^{\mathbf{1 1}}}$ state that this patient, at 18 months, was at his age level for language and personal-social functions, but at the 10 month level for gross fine motor performance, and Smith (1979, personal communication) reported that both boys were moderately mentally retarded. They also state that Visveshwara's case had a raucous cry, but there is no mention of the cry in the paper. Hassan states in the discussion that their patient had widening of the bifrontal diameter, although the description of the skull (their fig 4) notes widening of the bitemporal diameter. They emphasise that the distal hump of proximal phalanges 2 and 3 is slightly less narrow at 22 days than at 9 days and 
suggest that this is present in very young patients but 'one might expect . . . the abnormality could disappear'. However, the proximal middle phalanges are still abnormal at 3 months in one patient, ${ }^{7}$ and the middle phalanges were abnormal at 6 months, ${ }^{1}$ 9 months, ${ }^{2}$ and 10 months, ${ }^{6}$ so there is no evidence for the disappearance of this abnormality.

Bosch-Banyeras et $a^{12}$ compare their patient (their table 2) with the Marshall syndrome and the Weaver syndrome. The lower half of the table indicates that their patient resembles the Marshall syndrome, but not the Weaver in psychomotor retardation. However at 18 months the first patient of Weaver was at the 10 month level and we now know (Smith, 1979, personal communication) that both boys are retarded. As three of the ten Marshall patients have camptodactyly, ${ }^{1510}$ this cannot be used to distinguish the two syndromes.

Ferran $e t a l^{9}$ present some of the features of the patients of Marshall, Tipton, Visveshwara, Hassan, Weaver, and their own cases in their table 4, but their statements are controversial. According to this table, the Weaver patients have small facial bones (not stated or illustrated in the Weaver paper), have large proximal and middle phalanges with rounded distal ends (not stated in the paper or obvious in the photograph of the hand $x$-ray), and have angulated first metacarpals (this is not obvious in patient 1). In the article of Weaver et al $^{11}$ both patients are said to have camptodactyly; in their table, only one has camptodactyly. They also claim that Marshall's and Tipton's patients have an angulated first metacarpal, but neither is obvious. Hassan's case is said to have camptodactyly in the hands, but in the paper there is no mention of hand camptodactyly, only camptodactyly of the fourth left toe. They note that the baby 'showed a pathological increase in size' as in the Weaver syndrome. The weight at birth was $3900 \mathrm{~g}$ and no further weights are given. However, the second patient of Marshall was even larger; he weighed $4500 \mathrm{~g}$ at birth. The length of Ferran's patient was $55.5 \mathrm{~cm}$ at birth and $57 \mathrm{~cm}$ at 15 days. The second patient of Marshall was $63 \mathrm{~cm}$ in length at birth; Nábrády's patient was $57 \mathrm{~cm}$ at birth. This means that increased weights or lengths in the newborn cannot be used to distinguish the two syndromes. We believe that $x$-rays of the hands and of the head of Ferran's patient are an excellent example of the Marshall syndrome and do not resemble the head or hands of the Weaver syndrome.

The author is grateful to Dr L Pinsky for reviewing the manuscript, to Miss Christine Lalonde for the illustrations, and to Dr de Toni who sent copies of $\frac{\mathbb{D}}{\overparen{D}}$ the hand $x$-rays of his patient.

\section{References}

1 Marshall R, Graham C, Scott C, Smith D. Syndrome of $\overline{\bar{D}}$ accelerated skeletal maturation and relative failure to $\vec{\nabla}$ thrive: a newly recognized clinical growth disorder. $\triangle$ JPediatr 1971 ;78:95-101.

2 Nábrády J, Bozalyi I. Accelerált csontérés és somatomentalis retardatio újabb esete. Orv Hetil 1973;114: 2782-5.

3 Tipton R, Wilroy R, Summitt R. Accelerated skeletal $\vec{\omega}$ maturation in infancy syndrome: report of a third case. J Pediatr 1973;83:829-32.

4 Visveshwara N, Rudolph N, Dragutsky D. Syndrome of accelerated skeletal maturation in infancy, peculiar $\vec{v}$ facies, and multiple congenital anomalies. $J$ Pediatr 1974; 84:553-6.

' Hassan M, Sutton T, Mage K, Limal J, Rappaport R. The syndrome of accelerated bone maturation in the newborn infant with dysmorphism and congenital malformations. Pediatr Radiol 1976;5:53-7.

6 de Toni E, Duillo M, de Toni T, Cortese M, Bergamo F. Una rara sindrome con accelerazione della maturazione scheletrica. Minerva Pediatr 1976;28:1499-509.

- Perrin J, Arcinue E, Hoffman W, Chen H, Reed J. Accelerated skeletal maturation syndrome with pulmonary hypertension. Birth Defects 1976;12:209-17.

8 Iafusco F, D'Avanzo M, Ansanelli V. Su di un caso di accelerata maturazione scheletrica (sindrome di Marshall). Pediatria (Napoli) 1977;85:487-96.

9 Ferran J, Delcor Y, Senac J, Broche M. Accélération de la maturation osseuse du nouveau-né avec dysmorphie faciale, syndrome de Marshall-Smith. $J$ Radiol Electrol Med Nucl 1978;59:579-83.

10 Flatz S, Natzschka J. Syndrom der akzelerierten Skelettreifung vom Typ Marshall Kasuistik und Überblick. Klin Paediatr 1978;190:592-8.

11 Weaver D, Graham C, Thomas I, Smith D. A new overgrowth syndrome with accelerated skeletal maturation, unusual facies, and camptodactyly. $J$ Pediatr 1974;84: 547-52.

12 Bosch-Banyeras J, Salcedo S, Lucaya J, Laverde R, Boronat M, Marti-Henneberg C. Accélération du 3 developpement postnatal, hypertonie, elargissement des phalanges medianes et des metaphyses distales du femur, facies particulier: s'agit-il d'un syndrome de Weaver? Arch Fr Pediatr 1978;35:177-83.

13 Shimura T, Utsumi Y, Fujikawa S, Nakamura H, Baba K. Marshall-Smith syndrome with large bifrontal diameter, broad distal femora, camptodactyly, and without broad middle phalanges. J Pediatr 1979;94:93-5.

14 Moreno H, Zachai E, Kaufman H, Mellman W. Case report 18. Syndrome Identification $1974 ; 2: 22-5$.

15 Moreno H. Letter to the Editor. J Pediatr 1974;85:583.

16 Smith D. Comment. J Pediatr 1974;84:553.

Requests for reprints to Dr Naomi Fitch, Lady Davis Institute for Medical Research, Jewish General Hospital, 3755 Cote Saint Catherine Road, Montreal, Quebec, Canada H3T 1E2. 